\section{Konsep Dasa Paramartha pada Karakterisasi Tokoh Aji Dharma dalam Pertunjukan Wayang Tantri oleh I Wayan Wija}

\author{
I Dewa Ketut Wicaksandita ${ }^{1}$, Hendra Santosa, dan I Ketut Sariada \\ Program Studi Penciptaan dan Pengkajian Seni (S2), Program Studi Seni \\ Karawitan, Institut Seni Indonesia Denpasar
}

DANCé

jurnal tari, teater, dan wayang volume 3 number 1, May 2020 page $1-14$

\begin{abstract}
The Concept of Dasa Paramartha on the Characterization of Aji Dharma in a Wayang Tantri Performance by I Wayan Wija. Dasa Paramartha, as the teachings of dharma (goodness) in Hinduism, then becomes a material that is flexible enough to be displayed in broadcasting the meaning and value of ethical, moral, and social behavior education. Wayang Tantri, in the play of Sang Aji Dharma Kepastu presents the character of Prabu Aji Dharma with the characteristics trait displayed as a figure of dharma who later becomes a role model for Wayang Tantri audiences. This study aims to reveal the values of Dasa Parartha's teachings in the characterization of Aji Dharma figures. The qualitative descriptive method with data collection in the form of observation, interviews, and study documentation of the Wayang Tantri video of Sang Aji Dharma Kepastu with a duration of approximately 2 hours, then analyzed by, The Aesthetic Pedalangan Theory supported by Semiotic Theory. The results of the research are the representation of the teachings of Dasa Parmartha, which is in the form of Tapa: physical and mental self-control; Bharata: curb lust; Samadhi: mental concentration on God; Santa: being calm and honest; Sanmata: aspiring and aiming towards goodness; Karuna: affection between living beings; Karuni: compassion for plants, goods and so on; Upeksa: being able to distinguish right from wrong, good and bad; Mudhita: trying to please others; and Maitri: eager to seek friendship based on mutual respect.
\end{abstract}

Keywords: representation; Dasa Paramartha; Aji Dharma; Wayang Tantri

\section{Pendahuluan}

Artikel ini merupakan hasil penelitian pada program magister yang berjudul "Analisis Proses Perwujudan Wayang Tantri dan Bentuk Seni Rejang Sakral Sebagai Sebuah Seni Pertunjukan". Penelitian tersebut telah menghasilkan artikel yang berjudul "Estetika Gerak Tari Rejang Sakral Lanang di Desa Mayong, Seririt, Buleleng, Bali" yang diterbitkan oleh Jurnal Mudra, Jurnal Seni dan Budaya (Rianta, 2019) dan artikel yang berjudul "Kajian Estetis Adegan Bondres Wayang Tantri oleh Dalang I Wayan Wija" yang akan diterbitkan oleh Jurnal Panggung, Jurnal Seni Budaya ISBI Bandung.

Wayang diperkirakan lahir pada masa Bali Kuna sekitar masa pemerintahan Warmadewa dan merupakan salah satu produk kebudayaan yang masih eksis berkembang hingga saat ini di Bali (Santosa, 2017). Di Bali, para dalang melalui pengungkapan kreativitas dengan pengalaman otodidak ataupun akademi seninya. Ia berkutat dengan berbagai konsepsi dalam kehidupan sebagai landasan penciptaan dan metode dalam mengemas sajian pertunjukan seni, salah satunya wayang. Hal tersebut perlu dilakukan agar wayang

1 Alamat korespondensi: Program Studi Penciptaan dan Pengkajian Seni (S2), Program Studi Seni Karwitan, Institut Seni Indonesia Denpasar. Email: hendrasnts@gmail.com; HP.: 0818556949. 
sebagai media syiar ajaran agama yang penuh dengan ajaran etika, norma dan filsafat yang terkandung di dalamnya, dapat berjalan bersamaan dengan fungsi wayang sebagai media hiburan guna menghilangkan stres dan kepenatan pemirsanya. Maka dapat dikatakan bahwa pemilihan dan penuangan konsepsikonsepsi ajaran yang bersifat mendidik secara halus dalam berbagai instrumen pertunjukan wayang khususnya, merupakan sebuah cara yang agaknya perlu dilakukan oleh dalang dalam pengolaborasian karya seni yang bernuansa glokal (global-lokal), mengingat wacana yang muncul dalam perkembangan dan pembaharuan wayang kini yang masih dikatakan terombang-ambing dalam arus balinisasi dan globalisasi (Dibia, 2012: 61).

Adanya konsepi-konsepsi dalam penciptaan suatu karya seni merupakan salah satu landasan penting, yang kemudian memberikan bobot terhadap penyajian karya seni tersebut di kemudian hari. Dasa Paramartha (Netra, 1994: 42) sejatinya merupakan sebuah ajaran kerohanian dalam agama Hindu, yang dapat dipakai penuntun dalam tingkah laku yang baik serta untuk mencapai tujuan hidup yang tertinggi (moksa). Dikatakan bahwa Dasa Paramartha merupakan satu dari dua belas pelaksanaan dalam perbuatan baik Subhakarma yang merupakan sumber dari segala ajaran bertingkah laku yang baik dan mulia, sejalan dengan ajaran dharma (kebaikan). Adapun ajaran Subakarma dan Asubhakarma sendiri ialah terusan dari kitab suci Srasamuscaya 2 (Netra, 1994: 37-38). Pada uraiannya ajaran kebaikan Dasa Paramartha terbagi ke dalam sepuluh nama yaitu: tapa, bratha, samadhi, santa, sanmatha, karuna, karuni, upeksa, muditha, dan maitri kemudian dipahami sebagai salah satu wahyu Tuhan. Ajaran Hindu yang muncul sebagai manifastasi wahyu dari Tuhan kemudian dipahami sebagai dasar perbuatan dan perilaku manusia yang dilandasi iman yang menitikberatkan keyakinan bahwa kebenaran azasi adalah kebenaran yang didasari oleh wahyu Sang Maha Kuasa (Supartha, 1995: 126).
Adapun sekilas mengenai eksistensi ajaran dharma dalam pertunjukan wayang dikemukakan oleh S. Dananjaya dalam Supartha, dan kawan-kawan melalui buku Dharma Agama dan Dharma Negara (1995). Dananjaya melalui tulisannya banyak memunculkan tokoh-tokoh besar dalam dunia pewayangan seperti Gatotkaca dan keberaniannya berkorban menahan senjata konta dari Karna, demi membela dharma yang berpihak pada Pandawa dan negeri Indraprasta dalam cerita epik Mahabharata. Ada pula tokoh Wibisana yang memilih berpihak kepada Rama dalam menumpas keangkaramurkaan dari Rahwana yang merupakan saudara Wibisana sendiri dalam cerita epik Ramayana. Berdasarkan dari tulisan Dananjaya tersebut dapat disimpulkan bahwa integrasi ajaran agama telah menyatu dalam pengarakterisasian tokoh-tokoh pewayangan dan muncul melalui tindak-tanduk pada pengisahannya. Maka, dapat disimpulkan melalui tulisan tersebut bahwa wayang sebagai salah satu karya seni pertunjukan yang menarik dan menghibur, dapat dikemas sedemikian rupa sebagai media pendidikan ajaran dharma yang bermuatan etika, norma, dan estetika yang cukup berpotensi berkembang di masyarakat.

Walau kemudian I Kadek Suartaya (2007: 120) melalui kritikannya berjudul "Wayang Unggul Tersungkur Masgul" dalam buku Pentas Seni Ritus Bali (2007) mengatakan bahwa di Bali wayang masih bertahan karena disangga oleh ritual keagamaan masyarakatnya. Di samping itu, disebutkan pula bahwa wayang sebagai presentasi estetik pertunjukan wayang kulit tradisional telah kehilangan wibawa, kian termarjinal dalam kepungan tontonan masa kini. Namun dalam hal ini Suartaya juga menyajikan sebuah wacana angin segar terhadap eksistensi pewayangan dan pedalangan Bali. Dikatakan bahwa di tengah kegelisahan dan kegamangan eksistensi wayang Bali, reaktualisasi terhadap teater yang tergolong tua ini sudah menguak di Bali sejak dua puluh tahun terakhir 
(Suartaya, 2007: 120). Di antara pelopornya yang berangkat dari seniman alam serta akademisi, berasal dari kampung dalang di Desa Sukawati, Kabupaten Gianyar. Para pegiat seni pedalangan/pewayangan tersebut kini tengah berkutat dengan berbagai konsepsi estetis dalam mengemas pertunjukan wayang Bali garapan Baru. I Wayan Wija (Dalang Wija, 67 tahun) mucul dengan Wayang Tantri yang berkisah mengenai cerita fabel. Dikatakan Wayang Tantri tersebut masih kental mengacu pada pola konsep artistik wayang klasik.

Kemunculan dan keberadaan Wayang Tantri dari 1982-2018 oleh Dalang I Wayan Wija sebagai sebuah perbendaharaan baru dalam jenis wayang tradisi inovasi di Bali. Wayang Tantri mulanya merupakan pementasan wayang kulit dengan bentuk dan struktur pertunjukan tradisi Bali dengan cerita berbingkai yang mengisahkan perjalanan $\mathrm{Ni}$ Diah Tantri yang berkisah tentang hewanhewan (fabel), kemudian diperbaharui dengan kemunculan tokoh-tokoh hewan berpostur manusia atau tegak berdiri dan tokoh-tokoh punakawan (abdi) baru, seperti Pan Kayan, Pangkur, Kembar, dan Wijil.

Melalui salah satu lakon Wayang Tantri berjudul Sang Aji Dharma Kepastu dalam rekaman BaliRecord, muncul salah satu tokoh wayang yang didedikasikan berpihak kepada dharma yaitu tokoh Prabu Aji Dharma. Tokoh Aji Dharma dikisahkan sebagai seorang raja bijaksana yang mendapatkan ajian $A j i$ Panca Bhumi dan dapat berbicara dengan hewan berkat pertemanannya dengan Naga Antaboga. Uniknya, pada akhir alur cerita oleh Dalang Wija tersebut, tokoh Aji Dharma yang notabene berpihak dan menjalankan kebaikan malah mendapat hukuman tiga belas tahun pengasingan di hutan karena kejujurannya membedakan kebaikan dan keburukan dari Dewi Mayawati. Rupanya pengarakterisasian tokoh Aji Dharma oleh Dalang Wija dikatakan mengaku dilakukan sebagaimana interpretasi ajaran kejujuran dalam bertingkah berkata, berpikir dan bertingkah laku layaknya seorang raja yang bijaksana (wawancara, 21 Desember 2016). Hal ini kemudian dirasa mendekati perbuatan Muditha dan Maitri dalam ajaran Hindu Dasa Paramartha. Hal tersebut kemudian membuat peneliti menggali lebih dalam tentang pengarakterisasian tokoh Aji Dharma menyangkut ketokohan, kedudukannya sebagai raja yang menjadi media manifestasi dari ajaran Dasa Paramartha sebagai salah satu konsepsi dalam karakterisasi penokohan wayang Bali, yang diangkat melalui dua materi, yaitu pertama, konsep Dasa Paramartha dalam ajaran dharma agama Hindu; kedua, konsep Dasa Paramartha dalam karakterisasi tokoh Aji Dharma pada Wayang Tantri oleh Dalang I Wayan Wija.

Metode penelitian yang dipergunakan dalam proses penulisan karya ilmiah ini adalah metode kualitatif. Jhon W. Creswell dalam buku Penelitian Kualitatif dan Desain Riset (2015: 58) mengatakan bahwa penelitian kualitatif ialah suatu aktivitas yang menempatkan penelitianya di dunia. Lebih lanjut dikatakan bahwa penelitian kualitatif terdiri dari serangkaian praktik penafsiran material yang membuat dunia manjadi terlihat (Creswell, 2015: 58). Sejalan dengan definisi tersebut, penulis melakukan serangkaian proses (praktik) yang mempergunakan rangkaianrangkaian proses telaah dalam memperoleh dan menafsirkan secara sistematis bahanbahan yang dikaji sehingga menghasilkan suatu kesimpulan berdasarkan rumusan masalah (materi) yang diangkat.

Dalam penelitian kualitiatif ini dipergunakan jenis data primer dan data sekunder sebagai materi dasar dalam menelaah lebih jauh mengenai pokok bahasan yang akan dikaji, yakni konsep Dasa Paramartha dalam karakterisasi tokoh Aji Dharma pada Wayang Tantri oleh Dalang I Wayan Wija. Jenis data yang dimaksud ialah sebagai berikut. Dalam penelitian ini observasi langsung ke lapangan, yaitu di studio wayang I Wayan Wija yang bertempat di Br. Kalah, Desa Peliatan, Ubud, Gianyar. Hal ini dilakukan untuk mengetahui berbagai instrumen pentas yang dipergunakan 
dalam pementasan Wayang Tantri secara langsung sekaligus memperoleh data primer berupa hasil dokumentasi dan wawancara langsung. Observasi awal dilakukan pada tanggal 21 Desember 2016.

Metode wawancara tak terstruktur yang digunakan penulis yaitu mengajukan pertanyaan yang dirangkum secara umum dan mengembangkan lagi pertanyaan berdasarkan alur bahasan mengenai bagaimana penggunaan pencahayaan dalam Wayang Tantri. Melalui metode wawancara ini didapatkan rekaman berdurasi 1,5 jam yang isinya membahas seputar pengalaman berkreativitas, dan pengetahuan Dalang Wija seputar berbagai konsepsi ajaran Hindu yang kemudian ia tuangkan ke dalam tokoh-tokoh Wayang Tantri, khususnya tokoh Aji Dharma, serta hal-hal lainnya yang terkait dengan pokok bahasan.

Pada sumber diskografi diperoleh rekaman Wayang Kulit Tantri oleh Bali Record dengan dalang I Wayan Wija yang mementaskan lakon tantri "Sri Aji Dharma Kepastu" dengan durasi total \pm 2 jam yang penulis dapatkan dari sumbangsih narasumber I Dewa Ketut Wicaksana. Menjadi sebuah data sekunder yang berperan sangat besar dalam memberikan obyek yang selanjutnya dianalisis dalam teknis penggunaan blencong dan lampu. Analisis penulis selanjutnya disesuaikan dengan fakta lapangan dan diperkuat melalui kepustakaan terkait pencahayaan dan Wayang Tantri.

\section{Dasa Paramartha dalam Ajaran Dharma Agama Hindu}

Agama sebagai salah satu bagian dalam sistem kebudayaan, dipercayai memiliki semua unsur yang dapat memenuhi kebutuhan rohani manusia penganutnya. Ajaran yang terdapat di dalam agama pun mencakup pemahaman filosofis, pengetahuan, perilaku, dan sebagainya, yang diyakini dapat mengarahkan para pengikutnya ke arah ketenangan, kebahagian dan tujuan hidup yang tertinggi.
Agama sebagai pengetahuan kerohanian yang menyangkut soal-soal rohani yang bersifat gaib dan metafisika, secara etimologi berasal dari kata " $a$ " yang berarti tidak dan "gam" berarti pergi atau bergerak yang menggambarkan sifat-sifat kekekalan, abadi, dan tidak berubah dari Tuhan Yang Maha Esa (Netra, 1994:08). Sementara itu, Anthony F.C Wallace dalam Haviland, hasil alih bahasa Sokardijo berjudul Antropologi edisi ke-4 jilid 2 (1985) menyebutkan bahwa agama sebagai seperangkat upacara yang diberi rasionalisasi mitos, dan yang menggerakkan kekuatan-kekuatan supranatural dengan maksud untuk mencapai atau untuk menghindarkan sesuatu perubahan pada manusia atau alam (Soekadijo, 1985: 195). Hal ini didasarkan bahwa agama pada praktiknya melibatkan perilaku, sarana, dan kepercayaan yang didasarkan pada keyakinan pemeluknya dapat membangkitkan jiwa-jiwa supranatural di sekelilingnya guna menghindarkan manusia dari sesuatu bersifat relatif yang dianggapnya buruk. Maka selanjutnya pemahaman praktik terhadap ajaran agama diyakini oleh pemeluknya diturunkan melalui sabda dari Tuhan Yang Maha Esa, yang kemudian ajaran tersebut dipahami dan ditafsirkan melalui kitab-kitab suci.

Agama Hindu sebagai salah satu kepercayaan dengan mayoritas penganut khususnya di Bali, mempelajari saripati serta nilai-nilai kehidupan dalam Agama Hindu melalui banyak cara, salah satunya adalah melalui kitab suci Weda. Weda yang berasal dari kata "vid" dapat bermakna pengetahuan, serta dikatakan pula weda sebagai jiwa yang meresapi seluruh ajaran Hindu (Netra, 1994: 11). Weda dalam agama Hindu terbagai menjadi dua, yaitu pertama, Sruti, yang terdiri dari caturweda (Rg Weda Samitha, Sama Weda Samitha, Atharwa Weda Samitha, Yajur Weda Samitha). Kedua, Smerti, yang terdiri dari Wedangga (Siksa (phoetika); Wyakarana (tatabahasa); Chanda (lagu); Nirukta (penafsiran); Jyotisa (astronomi); Kalpa (tata cara yadnya); Upaweda (Itihasa (cerita epos Ramayana dan Mahabharata); Purana (cerita kuno penciptaan 
dunia, tentang raja-raja dan dewa-dewa); Arthasastra (ilmu pemerintahan); Ayurweda (ilmu kesehatan); Ghandarwaweda (ilmu seni) dan weda-weda lainnya (Netra, 1994: 13-18).

Uraian weda-weda di atas menyiratkan betapa luas dan kompleksnya pengetahuan yang seyogianya dipelajari guna memahami intisari dan nilai-nilai yang terdapat dalam ajaran Agama Hindu. Walau demikian luasnya upaya dalam memahami ajaran bisa dimulai dari kitab yang menguraikan hal ikhwal mengenai subhakarma dan asubhakarma 'benar' dan 'salah' atau 'baik' dan 'buruk'. Sebagaimana kenyataan dalam proses bersosial, manusia kerap kali dihadapkan dengan persoalaan perbedaan pendapat atau kerukunaan antarumat yang didasari dengan pengetahuan mengenai kebenaran dan kesalahan sehingga permasalahan perbedaan sudut pandang yang berujung krusial dapat diredam melalui pengetahuan tersebut. Ajaran mengenai subhakarma dan asubhakarma salah satunya muncul dalam kitab srasamuscaya yang berbunyi:

mānusah sarvabutheșu

vartate vai çhubāchube

açhubesu samaviștam

çhubesveva vākarāyet

(Srasamuscara: 2) (Netra, 1994: 37)

Terjemahan:

Dari demikian banyaknya makhluk hidup, yang dilahirkan sebagai manusia itu saja yang dapat melakukan perbuatan baik dan buruk itu, adapun peleburan perbuatan buruk ke dalam perbuatan baik juga manfaatnya jadi manusia.

Ajaran dalam kitab srasamuscaya yang merupakan intisari dari itihasa sebagaimana disampaikan di atas, menjelma menjadi ajaran subhakarma (perbuatan baik) yang terdiri dari Trikaya Parisudha; Catur Paramitha; Panca Yama Bharatha; Panca Nyama Bharatha; Sad Pramitha; Catur Aiswarya; Astha Siddhi; Nawa Sanggaha; Dasa Yama Bratha; Dasa Nyama Bratha; Dasa Dharma; Dasa Paramartha. Sementara itu, asubhakarma (perbuatan tidak baik) terdiri dari Trimala; Catur Pataka; Panca Bahya Tusti; Panca Wiparyaya; Sad Ripu; Sad Atatayi; Sapta Timira; Dasa Mala.

Dasa Paramartha dalam ranah pengetahuan mengenai kebaikan/subhakarma, dalam praktiknya kemudian menjadi sebuah konsep berpikir yang mengarahkan pelakunya untuk menerapkan nilai-nilai dan intisari dalam ajaran tersebut, guna dipakai menuntun tingkah laku yang baik dan mencapai tujuan hidup tertinggi, yakni moksa. Dasa Paramartha sendiri secara etimologi terdiri dari kata dasa yang berarti sepuluh dan paramartha yang berati kebenaran yang tertinggi. Lebih spesifik lagi, paramartha terdiri dari kata parama (yang utama) dan artha (tujuan) (Zoetmulder dan Robson, 2004: 64, 764 dan 766), yakni menyiratkan makna sepuluh perilaku yang utama yang dapat mengarahkan manusia mencapai tujuan utama (moksa).

Dasa Paramartha oleh masyarakat Hindu khususnya di Bali, ditafsirkan sebagai suatu ajaran berperilaku yang terbagi menjadi sepuluh bagian, antara lain pertama, tapa (pengendalian diri lahir batin). Umumnya, masyarakat memahami tapa sebagai sebuah tindakan mengasingkan diri dan melakukan sebuah perjalanan menuju suatu tempat yang dirasa mempunyai aura magis dan supranatural, kemudian pelaku tapa akan memusatkan pikiran dan tenaganya dalam satu posisi tertentu dan dalam tujuan tertentu. Konsep tapa saat ini umumnya dipraktikkan oleh masyarakat Hindu dengan cara mengendalikan diri secara lahir dan batin, misalnya dengan cara yoga atau olah tubuh, tidak rakus, makan dan minum secukupnya, serta instrospeksi diri dan bercermin pada kesalahan.

Kedua, bratha (mengekang hawa nafsu). Bratha, selain dipahami sebagai suatu pokok perilaku kebaikan yang mengutamakan pengekangan hawa nafsu, bratha juga dapat berarti 'cara hidup', 'tabiat', 'sikap', 'perilaku', bahkan dikatakan terdapat istilah suci-bratha bermakna cara hidup suci (Zoetmulder dan Robson, 2004: 134). Luaran perilaku yang 
umumnya dilakukan dalam pemahaman bratha ini di antaranya adalah berpuasa dari dan berlatih untuk mengontrol gaya hidup, emosional, tingkah laku, dan kebiasaan buruk dalam proses kehidupan sosial. Bahkan, dalam beberapa hari raya suci umat Hindu di Bali, salah satunya Hari Raya Nyepi, memandatkan masyarakat untuk mematuhi catur bratha, yaitu amatigeni (tidak menghidupkan api/ cahaya); amatilelungan (tidak bepergian keluar rumah); amatikarya (tidak melakukan pekerjaan); amatilelanguan (tidak membuat kebisingan/keributan). Makna yang lebih dalam diamati berkenaan dengan bratha pada ajaran Dasa Paramartha ialah berfokus untuk mengimbau pelaku agar dapat mengontrol setiap aktivitas yang menyangkut kehidupannya pribadi dengan hubungannya kepada Tuhan serta lingkungan di sekitarnya.

Ketiga, samadhi (konsentrasi pikiran kepada Tuhan). Samadhi oleh sebagian besar masyarakat dikenal sebagai suatu perilaku pemokusan konsentrasi dan pikiran kepada sang pencipta Tuhan Yang Maha Esa. Dikatakan pula samadi merupakan salah satu bagian pemusatan pikiran yang sangat dalam kaitannya dengan proses yoga (Zoetmulder dan Robson, 2004: 994). Umumnya samadhi pada masa ini dilakukan sebagai suatu praktik terhadap penguasaan ilmu kebatinan yang menyertakan doa-doa serta dilakukan di tempat suci, seperti pura. Dalam hal ini masyarakat pemeluk agama Hindu, salah satunya di Bali, mempraktikkan samadhi melalui persembahyangan tiga waktu. Persembahyangan umat Hindu yang dilakukan dalam posisi silasana (bersila) atau padmasana (bersimpuh). Pemusatan pikiran kemudian dilakukan dengan proses yang dinamakan pranayama pada saat ini pemusatan pikiran diikuti dengan proses penarikan napas penahanan dan pengembusan napas yang dilakukan sebanyak tiga kali, yang kemudian dilanjutkan dengan melantunkan lafalan Tri Sandya, yaitu lantunan doa pemujaan Tuhan Yang Maha Esa/Ida Sang Hyang Widhi Wasa. Dalam lantunan doa dan situasi khusyuk tersebut, proses pemusatan pikiran melalui penghayatan doa terjadi sebagai bentuk cinta kasih terhadap Tuhan.

Keempat, santa (selalu tenang dan jujur). Santa sebagai sebuah ajaran kebenaran menampakkan imbauan kepada pelakunya untuk selalu mawas diri dan tenang menghadapi segala permasalahan, serta pantang untuk berbohong pada setiap ucapan dan perkataan. Santa kemudian dimaknai dan kerap kali diterapkan dalam posisi sebagai seorang pemimpin. Salah satu contohnya muncul dalam kisah pewayangan epos Mahabharata, yaitu ketika Arjuna dengan kusirnya Krishna, titisan Dewa Wisnu, memasuki medan peperangan. Arjuna sebagai seorang kesatria dipaksa menghadapi guru, kakek, dan sepupu-sepupunya, para korawa. Pada mulanya Arjuna sempat merasakan kegusaran memikirkan sanak keluarga beserta seluruh pasukan dari seluruh jagat Bharatawarsa berperang membela dharma mereka masing-masing. Namun akhirnya ketenangan datang bersama dengan wejangan Krishna yang menyatakan kejujuran dari hakikat kehidupan yang sebenarnya. Peristiwa tersebut lebih dikenal dengan turunnya Bhagavad Gita. Pada akhirnya Arjuna bersama dengan para Pandawa dengan gagah berani serta tenang memasuki medan peperangan dan bertempur dengan gagah, memberantas keangkaramurkaan (adharma) hingga mencapai kemenangan. Dapat disimpulkan bahwa dalam kehidupan nyata, salah satu pemaknaan yang muncul adalah bagaimana manusia memahami serta mempraktikkan ajaran santa dalam mengarungi peperangan sebagai kiasan dari kehidupan, dan dapat memenangkan setiap masalah dengan mempelajari kejujuran sebagai landasannya.

Kelima, sanmatha, yakni tetap bercita-cita dan bertujuan terhadap kebaikan (Netra, 1994: 42). Ajaran sanmatha umumnya dipraktikkan sebagai sebuah usaha dalam menjunjung tinggi dharma dalam setiap perilaku dan pelaksanaan. Telah muncul dalam salah salah satu isi kitab sarasamuscaya 81 yang berbunyi: 
nihan ta krama ikang manah, bhnanta lunga svabhawannya, akweh meangen-angennya, dadi prathana, dadi sangsaya, pinakawaknya, hana pwa wawang ikang wenang humeret manah, sira tika menggah amanggih sukha, mangke ring para loka waneh (Srasamuscaya: 81) (Sura, 1985: 27)

Terjemahan:

Keadaan pemikiran itu demikian tidak berketentuan jalannya, banyak yang dicita-citakannya, terkadang penuh kesangsian, demikianlah kenyataanya, jika ada orang dapat mengendalikan pikirannya, pasti orang itu beroleh kebahagiaan, baik sekarang maupun di dunia yang lain

Di antara banyak perilaku dalam praktik ajaran sanmatha, mempelajari weda serta kitab suci dalam kepercayaan beragama merupakan salah satu contohnya, yakni pengetahuan tentang kebenaran yang diyakini menjadi jalan menuju cita-cita kehidupan yang damai dan sejahtera.

Keenam, karuna (cinta kasih sayang sesama makhluk hidup). Karuna mengajarkan umat Hindu untuk dapat lebih memerhatikan kondisi lingkungan di sekitarnya. Tafsir lebih mendalam terhadap ajaran ini melahirkan perilaku cinta kasih terhadap sesama serta lingkungan yang berdampak simbiosis bagi kehidupan manusia yang bersifat sosial itu sendiri. Salah satu bentuk pelaksanaan yang kerap dijumpai adalah bagaimana kehidupan bertetangga dapat terjalin rukun satu sama lainnya dalam satu wilayah tertentu, atau bagaimana atasan dapat menghormati bawahan dalam tataran struktur kepengurusan kerja dalam sistem sosial kemasyarakatan. Tentu saja hal ini sangat penting untuk dipahami, mengingat manusia bukanlah makhluk individual yang bisa hidup sendiri. Maka, bentuk cinta kasih yang ditunjukkan dengan ketulusan hati sangatlah perlu diketahui, dipahami, dan dipraktikkan bahkan sejak dini.
Ketujuh, karuni (belas kasih terhadap tumbuh-tumbuhan, barang, dan sebagaianya). Intisari dari ajaran samadhi dan karuna sebelumnya akan memiliki keterkaitan dengan ajaran karuni ini. Hal tersebutmengingatbahwa kepercayaan masyarakat pemeluk agama Hindu di Bali mengenal metafisis tiga dunia, yakni bhur (alam bawah: bhuta kala, arwah, dan jin); bwah (alam tengah: manusia dan segala hal ikhwal kehidupannya); swah (alam atas: para dewa, gandarwa, dan sebagainya). Tanpa disadari terdapat keterkaitan di antara ketiganya. Kenampakan tersebut dalam ajaran karuni oleh masyarakat Hindu, khususnya di Bali, muncul melalui pelaksanaan hari tumpeklandep serta tumpekkandang, yakni ketika masyarakat melaksanakan suatu yadnya yang berisikan upacara dan upakara yang ditujukan kepada berbagai peralatan serta hewan dan tumbuhan yang kerap memberikan bantuan dalam kehidupan manusia. Pada hari-hari tersebut para hewan serta alatalat penunjang hidup manusia diberlakukan dengan baik, selayaknya manusia menyayangi dirinya sebagai bentuk nyata cinta kasihnya.

Kedelapan, upeksa (dapat membedakan benar dan salah). Ajaran upeksa tampaknya muncul sebagai rangkuman dari kesepuluh ajaran dalam Dasa Paramartha yang saling memiliki keterkaitan. Ajaran upeksa sebagaimana tafsir yang dimunculkan, hendaknya merupakan suatu ajaran yang wajib dipahami oleh seluruh umat manusia. Sebab, manusia dikatakan sebagai makhluk yang dilahirkan dengan dua sifat yang saling mempengaruhi, yaitu baik dan buruk (rwabhineda) yang keduanya melalui kontrol etika dalam pikiran dan perilaku oleh manusia itu sendiri. Berikut ini kutipan dari kitab Srasamuscaya berkenaan dengan baik dan buruk.
Ri sakwehning sarwa bhuta, ikin janma wwang juga wenang gumawyaken ikang subhasubha karma, kuneng panentasakena ring subhakarma juga ikang subhakarma, pahalaning dadi wwang 
Apan sang hyang catur weda saha sadanggopangganira,

Sang hyang sangkya, sang hyang purana lawan ika kasujanman ikang kula keneng

Ika ta kabeh, tan katemu phalanya dening kadussilan, kalinganya, Wyartha weruhnya angaji lawan kasujanmannya

(Srasamuscaya: 2) (Sura, 1985: 28 dan 42)

Terjemahan:

Di antara semua makhluk hidup, hanya yang dilahirkan sebagai manusia sajalah yang dapat melaksanakan perbuatan baik dan buruk, leburlah ke dalam perbuatan baik, segala perbuatan buruk itu, demikian gunanya menjadi manusia.

Pengetahuan tentang kitab suci catur weda dengan enam cabang dan anak cabangnya, kemahiran tentang sastra suci sanghkya, purana dan kelahiran mulia dari suatu keturunan, semuanya itu tidak diperoleh buahnya, karena adanya kelakuan jahat, sehingga akhirnya pengetahuan dan kebahasawanannya tidak ada.

Dari kutipan di atas, tampak kiranya bagaimana manusia menjadi pusat dalam penentuan perilaku baik dan jahat yang muncul dan ada dalam dirinya, dan itu harus dikendalikan melalui luasnya pengetahuan. Begitupun bagi mereka yang telah mengetahui isi dan makna yang terkandung dalam intisari weda, tidak akan berguna apabila pengetahuan tersebut dilandaskan atau digunakan untuk melakukan hal yang buruk.

Kesembilan, muditha (selalu dapat menyenangkan orang lain). Ajaran mudita dalam tafsir peneliti ialah memunculkan makna bahwa masyarakat penganut ajaran Hindu di Bali menyadari bahwa ajaran baik dan buruk juga mengandung segala hal yang bersifat berlawanan, seperti senang dan sedih, mudah dan susah, dan sebagainya. Hal yang umumnya dijumpai melalui praktik dari mudita yang berarti kesenangan dan kegembiraan
(Zoetmulder dan Robson, 2004: 677) bisa berawal dari melakukan kejujuran serta bertindak secara arif dan bijaksana terhadap kerabat, orang asing yang tidak dikenal, serta lingkungan sekeliling kita. Niscaya kelakuan jujur dan bijaksana dalam menanggapi hal demikian menyebabkan kedua pihak, baik diri sendiri maupun lingkungan, menjadi senang dan terberkati.

Kesepuluh, maitri (suka mencari persahabatan atas dasar saling menghormati). Ajaran maitri sekaligus merupakan materi terakhir dalam konsepsi Dasa Paramartha yang diterapkan dalam berbagai pelaksanaan yang berkenaan dengan etika dan perilaku manusia. Maitri sendiri sudah sangat jelas menunjukkan bagaimana manusia yang merupakan makhluk sosial, menggunakan akal budinya untuk dapat berkomunikasi antarsesama serta membangun relasi yang luas guna kepentingan diri sendiri di masa kini dan yang akan datang. Bentuk materi dalam konsepsi maitri ini dapat dijumpai di segala lini. Sepanjang observasi yang dilakukan, hormat-menghormati sudah merupakan kebudayaan yang dilakukan oleh masyarakat berkenaan dengan pengetahuan dan sistem kemasyarakatan. Sebut saja hubungan persahabatan antara guru dan siswa yang terjalin berkat rasa saling menghormati antara satu dan yang lainnya, atau sebagaimana contoh yang dimunculkan dalam cerita epik Ramayana dalam itihasa, yakni ketika Sri Rama menghormati kedatangan Wibisana yang telah menentukan dharmanya kepada Sri Rama. Dalam hal ini, dharma yang bersifat relatif dalam konteks rwa bhineda yang tak terlepas satu sama lainnya, akan lebih efektif muncul dan mudah dibedakan dalam pemahaman melalui cerita-cerita demikian.

Dengan dianalisisnya Dasa Paramarta sebagai sebuah konsep berpikir dan berperilaku yang berlandaskan ajaran darma (kebaikan), dapat ditarik benang merah bahwa ajaran ini bersifat multiaplikatif yang bermakna bisa dipergunakan dan diaplikasikan pada berbagai media. Selain 
muncul pada media sastra dan juga fenomena aktivitas kehidupan masyarakat masa kini, ajaran ini dapat direpresentasikan ke dalam wujud-wujud yang lebih komunikatif. Dengan demikian, nilai dan abstraksi konsep yang masih bersifat multitafsir dapat dipahami dengan dalam satu persatu dan akhirnya secara menyeluruh dalam konteks fungsi Dasa Paramartha pada kehidupan masyarakat.

\section{Konsep Dasa Paramartha dalam Karakterisasi Tokoh Aji Dharma pada Wayang Tantri oleh Dalang I Wayan Wija}

Sebuah karya seni yang unggul, sudah seyogianya mengandung nilai-nilai yang dapat berguna bagi kehidupan seniman dan masyarakat penikmat ataupun pendukungnya. Maka, pematangan terhadap mutu dan kualitas suatu karya seni sangat dipengaruhi oleh pondasi konsep yang sangat mempengaruhi kemunculan nilai-nilai yang dapat dipetik dan berguna dalam kehidupan seniman ataupun apresiator atau pemirsannya. Pembahasan mengenai karya seni mengacu kepada cabang ilmu estetika yang di dalamnya sudah pasti terkandung konsepsi-konsepsi keindahan yang menyebabkan adanya nilai estetis dalam karya seni yang muncul. Sebagaimana definisinya, konsep muncul sebagai sebuah gambaran abstrak dengan berbagai persepsi, ide, rencana sarana, analisis terhadap masalah dan sebagainya yang menyebabkan seniman bereaksi memunculkannya lewat karya seni.

Dasa Paramartha yang merupakan ajaran kebajikan, sebagaimana diuraikan pada pembahasan sebelumnya, mengacu pada konsep keindahan atau estetika India yang dikatakan tidak dapat terlepas dari agama Hindu dan Buddha (Agung, 2017: 75). Dapat dikatakan bahwa kedua agama tersebut menganut konsep kehidupan yang berpandangan bahwa waktu terus berulang, yakni semesta dihancurkan dan diciptakan kembali, dan seterusnya; dunia tidak nyata (maya); manusia bereinkarnasi (samasara); perbuatan baik akan dibalas dengan perbuatan baik dan jahat akan dibalas dengan kejahatan (karma). Oleh sebab itu, manusia harus berbuat baik agar terlepas dari lingkaran waktu (moksa). Dikatakan pula pandangan kedua agama tersebut hampir sama mengenai kehidupan para dewa-dewi, setan (raksasa), manusia, hewan, dan alam permai yang saling terhubung sebagai kesatuan semesta (Kosak dan Watts, dalam Agung, 2017: 76). Konsep demikian kemudian terfiltrasi menjadi ajaranajaran yang oleh para seniman dimunculkan melalui karya seninya sehingga akan tampak bahwa memang terdapat intisari yang oleh seniman bersangkutan dianggap mempunyai bobot atau cerminan hidup bagi manusia di sekelilingnya.

Aji Dharma (Anglingdharma) merupakan salah satu karakter wayang dalam pentas Wayang Tantri berjudul Sang Aji Dharma Kepastu oleh I Wayan Wija (Dalang Wija), yang dimunculkan sebagai sosok raja yang halim dan bijaksana. Kisah Aji Dharma sendiri muncul dalam karya sastra kidung tantri nandaka harana dan pisacaharana yang merupakan salah satu karangan sastra cerita bertembang berbingkai dengan tema kehidupan manusia dan fabel (hewan-hewan). Hal yang menarik dari tokoh Aji Dharma dalam pentas Wayang Tantri oleh Dalang Wija adalah terintegrasinya konsep Dasa Paramartha dalam pengisahannya. Seperti bentuk aplikasi ajaran Dasa Paramartha dalam agama Hindu pada uraian sebelumnya, Aji Dharma sebagai seorang raja dalam pementasan wayang yang digelar berdurasi lebih kurang dua jam dan terbagi dalam dua babak, sepenuhnya memperlihatkan adeganadegan, tindak-tanduk, serta bentuk fisik tokoh sebagai elemen-elemen yang mempengaruhi karakterisasinya yang terintegrasi dengan konsep Dasa Paramartha pada ajaran mengenai kebaikan (dharma).

Adapun lakon Sang Aji Dharma kepastu pada pementasan wayang oleh Dalang Wija sesuai pembabakan dapat simak sebagai berikut. 


\section{Babak I (Adegan: Prolog, Paruman [rapat] di Kerajaan, dan Adegan Rakyat)}

Dikisahkan bahwa setelah Naga Anantaboga mendapati Sang Prabu yang telah melaporkan Puti Naga Gini mencurangi ayahnya Naga Anantaboga, Ajian Panca Bumi pun diberikan Sang Naga Antaboga kepada Prabu Anglingdharma (Sang Aji Dharma). Anantaboga berpesan bahwa Ajian Panca Bumi, yakni ilmu yang mempunyai kesaktian dapat mengetahui semua bahasa binatang, tidak boleh diberitahukan kepada siapa pun, bahkan anak dan istrinya. Kalau berani melanggar pesan ini, maka Prabu Anglingdharma akan mati. Oleh karena itu, Anglingdharma sangat memperhatikan nasihat dan pesan Naga Anantaboga. Setelah semuanya selesai, Anantaboga meminta mereka bersama memejamkan kedua matanya. Tiba-tiba saja, Prabu Anglingdharma merasa terbang ke angkasa dan tiba kembali di Istana Malawapati. Sementara itu, Naga Anantaboga moksa dan menghilang.

Setelah lama berselang sejak kejadian itu, diceritakan Dewi Setyawati dan Prabu Anglingdarma sedang memadu cinta di kamar tidurnya. Ketika itu terdengar suara dua ekor cicak sedang bercengkerama. Namun, karena keadaan cicak betina yang sedang mengandung, ia pun memprotes cicak jantan yang dengan seenaknya ingin berhubungan dalam kondisinya akan segera bertelur. Disebabkan karena nafsunya cicak jantan, maka semakin keraslah perdebatan yang terjadi antra cicak jantan dan betina. Mendengar pembicaraan kedua cicak tersebut, Prabu Anglingdharma menjadi ketawa terpingka-pingkal. Setyawati terkejut mendengar suaminya ketawa geli. Prabu Anglingdharma menceritakan perihal perdebatan cicak jantan dan betina itu. Namun, karena tidak yakin dan percaya dengan cerita Anglingdharma, maka Dewi Setyawati menjadi marah dan sakit hati. Ia merasa tidak pantas menjadi istri Prabu Anglingdharma karena ia gadis desa, tidak cantik, dan tidak bisa tatakrama, seperti para priyayi kerajaan lainnya. Kemarahan sang istri berbuntut pan- jang. Sang istri berkata, "Kalau Prabu Anglingdharma mengerti apa yang dikatakan cicak, mengapa saya tidak boleh tahu apa yang dikatakan cicak?" tanya sang istri.

Mendengar hal itu, Prabu Anglingdharma tidak bisa menerangkan apa sebenarnya yang baru dialaminya, yaitu telah menerima Aji Panca Bumi dari Naga Anantaboga. Ajian itulah yang menjadikannya mengerti apa yang dikatakan cicak. Prabu Anglingdharma meminta Dewi Setyawati untuk mau mengerti kalau dirinya masih dalam kesulitan. Dewi Setyawati minta diajari bahasa cicak. Ia ingin dengar sendiri pembicaraan mereka namun Prabu Anglingdharma tidak bisa memberikan atau mengajari bahasa cicak itu. Oleh karena alasan suaminya tidak bisa meyakinkan dirinya, maka Dewi Setyawati lebih percaya kalau tadi ia benar-benar menertawakan dirinya. Ia merasa sangat malu. Akhirnya, Dewi Setyawati ingin bunuh diri dengan menceburkan dirinya ke dalam api daripada dipermalukan oleh suaminya sendiri.

Prabu Anglingdharma pun memanggil Patih Madri, meminta pendapatnya, sehubungan ada permintaan dari permasuri raja, Dewi Setyawati. Sang Patih pun bersedia melakukan negosiasi demi mencegah sang permaisuri melakukan tindakan bunuh diri. Namun, niat Dewi Setyawati sudah tidak bisa diubah. Pendiriannya untuk tidak melakukan perbuatan konyol dengan membakar diri, sudah tidak bisa dicegah. Maka, untuk menunjukkan kecintaannya kepada sang istri, maka Prabu Anglingdharma dengan hati rela akan melakukan seperti apa yang akan dilakukan istrinya, yaitu turut serta membakar diri. Keesokan harinya para perajurit menyiapkan tempat pembakaran. Dibuatlah sebuah panggung hampir setinggi dua atau tiga kali tinggi rumah, dengan bentuk hampir seperti sebuah menara. Di sekeliling panggung itu dihias janur kuning untuk menyemarakkan suasana. Adapun Prabu Anglingdharma dan Dewi Setyawati telah menyiapkan diri untuk melakukan pembakaran bersama. Kayukayu bakar pun sudah mulai dihidupkan dan 
api mulai menyala. Sementara itu, di dekat panggung, ada sepasang kambing jantan dan kambing betina. Kambing betina yang kelihatan gelisah, meminta kambing jantan agar diambilkan daun janur yang menempel di dekat Dewi Setyawati. Mendengar kata-kata kambing betina, kambing jantan menjawab, "Mengambilkan daun janur di atas sana... yang benar saja??? Letaknya saja di atas sana, di atas panggung yang amat tinggi, bisa bisa badanku yang terbakar!" Namun, kambing betina itu semakin merajuk dan berkata, "Kalau kamu tidak mau mengambilkan daun janur itu, aku akan mati bakar diri saja seperti Dewi Setyawati." Kambing jantan pun marah dan menjawab, "Kalau mau bakar diri, silakan saja, tetapi aku tidak mau seperti Raja Anglingdharma. Gampang sekali ikut melakukan bakar diri. Kalau aku, tak sudi melakukan hal itu."

Api sudah berkobar bagai mau mencapai langit. Sementara itu, Prabu Anglingdharma sedang senyum-senyum sendiri ketika mendengar pembicaraan kedua kambing itu. Melihat suaminya tersenyum-senyum dan sedang terlena, Dewi Setyawati, tanpa diketahui oleh Prabu Anglingdharma, terjun dalam kobaran api yang amat besar. Prabu Anglingdharma belum sadar juga kalau istrinya sudah terjun terlebih dahulu ke dalam kobaran api. Ketika tersadar dari lamunannya, Prabu Anglingdharma tinggal seorang diri. Ia ditinggal Dewi Setyawati yang terjun mendahuluinya. Tanpa diduga, kobaran api yang tadinya besar semakin mengecil dan berujung padam. Anglingdharma pun mengurungkan niatnya untuk mengikuti istrinya membakar diri.

Sepeninggal istrinya, Prabu Anglingdharma berniat melakukan upacara penyucian dan berkabung. Untuk itu, dipanggillah Patih Madri untuk mempersiapkan segala sarana dan prasarananya. Sang Prabu pun memerintahkan agar para pekerja disarankan terdiri dari laki-laki untuk menghindarkan pikiran yang membuatnya mengenang kembali sang istri yang telah tiada.
Seluruh masyarakat pun bergembira dan mendukung pelaksanaan yadnya yang akan digelar oleh Sang Raja Anglingdharma. Tak ketinggalan, para hewan seperti anjing, kambing, babi, dan tumbuh-tumbuhan seperti bambu-bambu, bersuka cita turut menghaturkan yadnya kepada sang raja demi kelancaran pelaksanaan yadnya.

\section{Babak II (Adegan: Dewi Mayawati, Raksasa, Perang, Pengasingan)}

Di tempat lain dikisahkan dua orang abdi Dewi Mayawati sedang bersiap-siap menyambut dan mengiringi sang dewi untuk pergi ke kerajaan Prabu Anglingdharma. Ia diiringi oleh para raksasa dan antek-antek onar yang siap membalaskan dendam ideologi istri sang prabu melalui Dewi Mayawati.

Dikisahkan di pinggiran kerajaan ketika yadnya sedang belangsung, tiba-tiba Sang Prabu dihadang oleh Dewi Mayawati. Ia bertanya kepada Sang Prabu yang diketahuinya sangat jujur mengenai perbandingan kecantikanya dengan para dewi di seluruh negeri. Bahkan, ia dengan berani menanyakan perbandingan dirinya dengan Dewi Uma di khayangan. Prabu Anglingdharma yang tidak berani akan kekuasaan para dewa di

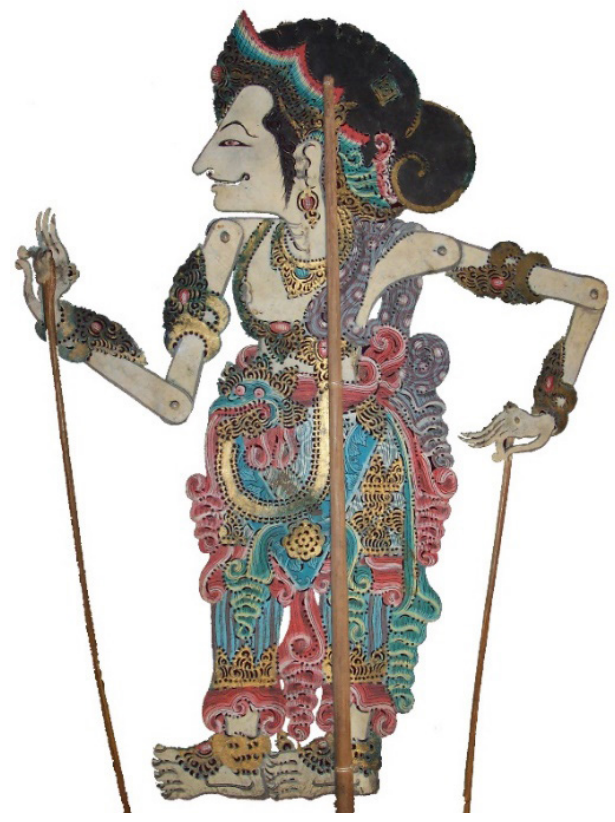

Gambar 1. Wayang Aji Dharma karya I Wayan Wija (Dalang Wija). (Sumber: IDK Wicaksandita) 
khayangan menjawab bahwa kecantikan Dewi Mayawati memang sepadan dengan para ratu dan dewi di khayangan namun tingkah laku dan bahasa tubuhnya, menurut Anglingdharma, menyerupai laki-laki. Mendengar perkataan Sang Parbu, Dewi Mayawati pun marah bukan kepalang. Dicacinya Anglingdharma yang dirasa telah menghina dan menjatuhkan harga dirinya. Pertarungan pun terjadi di antara mereka.

Kesaktian keduanya sangatlah dahsyat namun apa daya Sang Prabu. Akhirnya, Dewi Mayawati yang mempunyai kesaktian maya loka (memindahkan alam sekitar), mengutuk Sang Prabu untuk bertapa di tengah hutan lebat selama duabelas tahun sebagai ganti atas hinaan Sang Prabu pada seorang wanita, terlebih ia telah mengingkari janjinya pada sang istri untuk turut serta terjun ke dalam api. Merasa bahwa dirinya bernar-benar salah, Sang Prabu pun menerima dengan ikhlas pengasingan tersebut. Ia ditemani oleh abdinya yang setia.

Berkenaan dengan karekterisasi yang meliputi perwatakan dan penokohan dalam pertunjukan wayang, Hadiprayitno dalam buku Teori Estetika untuk Seni Pedalangan (2004: 67) menyatakan bahwa melukiskan perwatakan dan penokohan dalam lakon wayang dapat dilakukan dengan beberapa cara di antaranya: (1) melukiskan bentuk lahir tokoh; (2) melukiskan jalan pikiran atau apa yang telintas dalam pikiran tokoh; (3) reaksi tokoh terhadap suatu kejadian; (4) dalang langsung

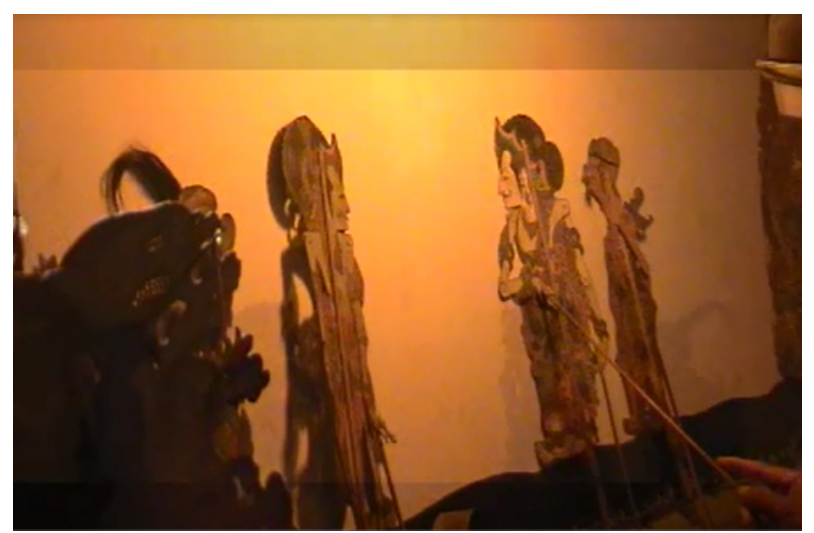

Gambar 2. Wayang Aji Dharma (dua dari kanan ke kiri) dalam pentas Wayang Tantri oleh I Wayan Wija (Dalang Wija). (Sumber: Bali Record) menganalisis watak tokoh; (5) melukiskan keadaan sekitar tokoh; (6) pandangan tokoh terhadap tokoh lainnya. Pendekatan terhadap pemilihan wayang juga dilakukan oleh Sedana dalam disertasinya berjudul Kawi Dalang Creativity in Wayang Thetre (2002). Ia mengemukakan, “....Using principle of wanda the performance of wayang infolves a selecting puppets to represent the dramatic characters which are thoroughly defined by the play that dalang selected..." (Sedana, 2002: 132). Dikatakan bahwa penggunaan prisip wanda, pertunjukan wayang juga menyangkut pemilih an wayang yang mempresentasikan struktur dramatik dari karakter, yang mengikuti pemilihan tema cerita yang dipentaskan oleh dalang. Berdasarkan kedua pendapat tersebut, kemudian akan menguraikan aspek-aspek karakterisasi yang selanjutnya disinkronisasikan melalui analisis makna guna memperlihatkan konsep Dasa Paramartha pada tokoh Aji Dharma dalam lakon wayang Sang Aji Dharma Kepastu oleh Dalang Wija.

Analisispemaknaanyangmunculterhadap karakterisasi tokoh Aji Dharma selanjutnya tertuang dalam tabel yang menguraikan berbagai aspek dan elemen-elemen yang memperlihatkan jalinan bentuk dari konsep Dasa Paramartha dalam karakterisasi tokoh Aji Dharma. Anailisis tersebut sebagaimana muncul dalam tabel analisis yang melibatkan berbagai aspek karakterisasi, tema, wujud tokoh, dan unsur-unsur karakterisasi tokoh.

\section{Penutup}

Pertunjukan wayang yang kaya akan filosofi dan nilai-nilai social-religius merupakan salah satu wahana pendidikan yang senantiasa mengarahkan penonton atau apresiatornya untuk mengupas lebih dalam mengenai norma, etika kehidupan bermasyarakat melalui sajian pertunjukan wayang yang dikemas secara adaptif menggunakan berbagai pola perwujudan yang kreatif oleh sang dalang. Di Bali, wayang tidak hanya muncul sebagai sebuah wujud 
representasi estetis dalam pelaksanaan kegiatan beragama, tetapi wayang dengan segenap bangun estetis di dalamnya juga terbentuk dari nilai-nilai serta pemahaman terhadap konsep beragama. Maka dapat dikatakan bahwa integrasi dalam hubungan saling timbal balik melalui filosofi dan daya kreativitas dalang telah membangun pertunjukan wayang sebagai sebuah pertunjukan seni yang adiluhur.

Adanya konsep ajaran agama Hindu, salah satunya Dasa Paramartha, yang terintegrasi pada tokoh Aji Dharma dalam pementasan Wayang Tantri oleh I Wayan Wija merupakan salah bentuk integrasi ajaran agama yang divisualkan melalui elemen-elemen karakterisasi tokoh. Misalnya, bentuk lahiriah tokoh, pandangan tokoh lain terhadap tokoh yang dibahas, pikiran tokoh, pandangan tokoh terhadap reaksi, dan lain-lain. Berdasarkan analisis terhadap konsep Dasa Paramartha Tapa: pengendalian diri lahir dan batin; Bharata: mengekang hawa nafsu; Samadhi: konsentrasi pikiran kepada Tuhan; Santa: selalu tenang dan jujur; Sanmata: selalu bercita-cita dan bertujuan terhadap kebaikan; Karuna: cinta kasih sayang sesama makhluk hidup; Karuni: belas kasih terhadap tumbuhtumbuhan, barang, dan sebagaianya; Upeksa: dapat membedakan benar dan salah, baik dan buruk; Mudhita selalu berusaha untuk dapat menyenangkan hati orang lain; Maitri: selalu suka mencari persahabatan atas dasar saling menghormati. Representasi Dasa Pramartha melalui tokoh Aji Dharma muncul melalui karakternya, yaitu pertama, visual tokoh; kedua, berkehendak melakukan dharma melalui yadnya; ketiga, dihormati oleh tokoh wayang lainnya; keempat, gemar berderma dan mencari sahabat, dibuktikan dengan diberikannya kesaktian Aji Panca Bhumi oleh Sang Naga Anantaboga; kelima, berkedudukan sebagai seorang raja di sebuah negeri yang makmur; keenam, berlaku jujur ketika memberi penilaian terhadap Dewi Mayawati berkenaan rupa dan kemolekan wajahnya yang diperbandikan dengan Dewi Sri.
Dapat ditarik kesimpulan bahwa pementasanWayangTantridengankemunculan tokoh Aji Dharma yang berkarakterkan konsep Dasa Pramartha, mempunyai bobot dan nilai yang dapat dijadikan suritauladan bagi para pemirsa atau audiens yang menyaksikan pertunjukan Wayang Tantri oleh Dalang Wija. Selain konsepsi Dasa Paramartha, masih banyak lagi konsepsi yang sangat ideal untuk dituangkan dalam berbagai aspek dan elemen perwujudan dalam pementasan wayang sebagai media syiar yang baik. Hal ini haruslah terus didengungkan, mengingat konsep agama dan kesatuan dalam proses kehidupan sosialreligius telah menjadi nyawa bagi sistem kebudayaan masyarakat Bali dan Indonesia pada umumnya.

\section{Kepustakaan}

Agung, Lingga. 2017. Pengantar Sejarah dan Konsep Estetika. Yogyakarta: PT. Kanisus. Creswell, J. W. 2015. Penelitian Kualitatif dan Desain Riset. Yogyakarta: Pustaka Pelajar.

Dibia, I Wayan. 2012. Geliat Seni Pertunjukan Bali. Denpasar: Buku Arti.

Hadiprayitno, Kasidi. 2004. Teori Estetika untuk Seni Pedalangan. Yogyakarta: Lembaga Penelitian Institut Seni Indonesia.

Netra, Anak Agung Gede Oka. 1994. Tuntunan Dasar Agama Hindu. Jakarta: Hanuman Sakti.

Rianta, I Ketut Sariada; Hendra Santosa; I Made. 2019. "Estetika Gerak Tari Rejang Sakral Lanang di Desa Mayong, Seririt, Buleleng, Bali." MUDRA Jurnal Seni Budaya 34(3): 385-93. https://jurnal. isi-dps.ac.id/index.php/mudra/article/ view/678.

Santosa, Hendra. Nina Herlina Lubis, Kunto Sofianto, RM. Mulyadi. 2017. "Seni Pertunjukan Bali pada Masa Dinasti Warmadewa." MUDRA Jurnal Seni Budaya 32(1): 81-91. http://jurnal.isi-dps.ac.id/ index.php/mudra/article/view/8.

Sedana, I Nyoman. 2002. "Kawi Dalang: 
Creativity in Wayang Theatre." University Brown.

Soekadijo, R.G. 1985. Antropologi, Edisi ke Empat Jilid 2. Jakarta: Erlangga.

Suartaya, I Kadek. 2007. Pentas Seni Ritus Bali. Denpasar: Buku Arti.

Supartha, Wayan, DKK. 1995. Dharma Agama dan Dharma Negara. Denpasar: PT. BP.

Sura, I Gede. 1985. Pengendalian Diri dan Etika dalam Ajaran Agama Hindu. Jakarta: Hanuman Sakti.

Zoetmulder, PJ dan Robson, S.O. 2004. Kamus Jawa Kuna Indonesia. Jakarta: PT. Gramedia Pustaka Utama. 